\title{
Trajectories of Suffering in the Last Year of Life Among Patients With a Solid Metastatic Cancer
}

\author{
Chetna Malhotra, MD ${ }^{1,2}$; Rahul Malhotra, MD2,3; Filipinas Bundoc, MA ; Irene Teo, $\mathrm{PhD}^{1,4}$; Semra Ozdemir, $\mathrm{PhD}^{1,2}$; \\ Noreen Chan, $\mathrm{MD}^{5}$; and Eric Finkelstein, $\mathrm{PhD}, \mathrm{MHA}^{1,2}$
}

\begin{abstract}
Background: Reducing suffering at the end of life is important. Doing so requires a comprehensive understanding of the course of suffering for patients with cancer during their lastyear of life. This study describes trajectories of psychological, spiritual, physical, and functional suffering in the last year of life among patients with a solid metastatic cancer. Patients and Methods: We conducted a prospective cohort study of 600 patients with a solid metastatic cancer between July 2016 and December 2019 in Singapore. We assessed patients' psychological, spiritual, physical, and functional suffering every 3 months until death. Data from the last year of life of 345 decedents were analyzed. We used group-based multitrajectory modeling to delineate trajectories of suffering during the last year of a patient's life. Results: We identified 5 trajectories representing suffering: (1) persistently low (47\% of the sample); (2) slowly increasing (14\%); (3) predominantly spiritual (21\%); (4) rapidly increasing (12\%); and (5) persistently high (6\%). Compared with patients with primary or less education, those with secondary (high school) (odds ratio [OR], 3.49; 95\% Cl, 1.05-11.59) education were more likely to have rapidly increasing versus persistently low suffering. In multivariable models adjusting for potential confounders, compared with patients with persistently low suffering, those with rapidly increasing suffering had more hospital admissions $(\beta=0.24 ; 95 \%$ $\mathrm{Cl}, 0.00-0.47)$ and hospital days $(\beta=0.40 ; 95 \% \mathrm{Cl}, 0.04-0.75)$ during the last year of life. Those with persistently high suffering had more hospital days ( $\beta=0.70 ; 95 \% \mathrm{Cl}, 0.23-1.17)$. Conclusions: The course of suffering during the last year of life among patients with cancer is variable and related to patients' hospitalizations. Understanding this variation can facilitate clinical decisions to minimize suffering and reduce healthcare costs at the end of life.
\end{abstract}

J Natl Compr Canc Netw 2021;19(11):1264-1271 doi: 10.6004/jnccn.2021.7014

${ }^{1}$ Lien Centrefor Palliative Care, ${ }^{2}$ Program in Health Services and Systems Research, and ${ }^{3}$ Centre for Ageing Research and Education, Duke-NUS Medical School; ${ }^{4}$ National Cancer Centre Singapore; and ${ }^{5}$ Division of Palliative Care, National University Cancer Institute, Singapore.

\section{Background}

Approximately 9.5 million patients with cancer die each year. ${ }^{1}$ By 2040 , this number is projected to increase to more than 16 million. ${ }^{1-4}$ Alleviating suffering at the end of life is a core component of cancer and palliative care services. The Lancet Commission on Palliative Care and Pain Relief and the 2014 World Health Assembly resolution have also emphasized the urgency to reduce suffering at the end of life. ${ }^{5,6}$ Doing so requires a comprehensive understanding of the course of suffering for patients with cancer during their last year of life.

Suffering is conceptualized to have multiple dimensions, including psychological, spiritual, physical, and functional. ${ }^{7-11}$ However, existing studies focus only on a single dimension of patients' suffering, such as functional decline (functional suffering) or physical symptoms (physical suffering), and their trajectories (ie, patterns of change) during the last year of life. ${ }^{12-17}$ An inclusive description of trajectories of suffering, concurrently spanning different dimensions for patients with cancer, namely psychological, spiritual, physical, and functional, is lacking. Heterogeneity in the course of suffering during the last year of life has also not been examined.

We therefore aimed to delineate the trajectories of psychological, spiritual, physical, and functional suffering during the last year of life in patients with a solid metastatic cancer, and to assess patient sociodemographics that predict membership of delineated trajectories. Studies show variation in health and suffering by education. ${ }^{18-23}$ Studies also report that older patients with cancer experience more functional suffering ${ }^{24-26}$ and those with no religious affiliation are likely to have greater spiritual suffering. ${ }^{27}$ We thus hypothesized that patients with low education will be more likely to have trajectories with greater suffering across all the considered dimensions; older patients will be more likely have trajectories representing greater functional suffering; and those with no religious affiliation will have trajectories with greater spiritual suffering.

See JNCCN.org for supplemental online content. 
To understand whether the trajectories of suffering differ in other meaningful ways, we also assessed whether healthcare utilization (hospitalizations and use of palliative/hospice care services) during the last year of life and place of death vary across the delineated trajectories. Previous studies have reported that repeated hospitalizations are associated with worse physical symptoms, functional status, and psychological distress. ${ }^{28-31}$ Studies also show that patients with a higher symptom burden are also more likely to be referred to a palliative/hospice care service and to die in the hospital or hospice compared with home. ${ }^{32-34}$ We thus hypothesized that patients who have trajectories indicative of greater suffering will also have more hospitalizations, be more likely to have received palliative or hospice care, and to die in hospice.

\section{Patients and Methods}

\section{Study Design, Setting, and Participants}

We used data from Cost of Medical Care of Patients with Advanced Serious Illness in Singapore (COMPASS). This is a longitudinal study of 600 patients with a solid metastatic cancer followed-up every 3 months until death. A detailed description of it has been published elsewhere. ${ }^{35}$

Between July 2016 and March 2018, we recruited patients from outpatient clinics at medical oncology departments of 2 major public hospitals in Singapore. Because the overall goal was the longitudinal assessment of end-of-life outcomes, we recruited patients with stage IV solid malignancy. Eligible patients were aged $\geq 21$ years (cutoff age for independent consent), Singapore citizens or permanent residents, and cognitively able to consent and self-report (determined through medical records or Abbreviated Mental Test ${ }^{35}$ administered to participants aged $\geq 60$ years), and had ECOG ${ }^{36,37}$ performance status $\leq 2$ (to allow a period of follow-up before end of study). The study was approved by the SingHealth Centralised Institutional Review Board (2015/2781).

\section{Study Variables}

\section{Outcome}

We assessed 4 dimensions of suffering: psychological, spiritual, physical, and functional. We used the 14-item Hospital Anxiety and Depression Scale to assess psychological suffering. ${ }^{35,38-40}$ A higher total score (range, 0-42) represented greater psychological suffering. To assess spiritual suffering, we used the 12-item Functional Assessment of Chronic Illness Therapy-Spiritual Well-Being scale. ${ }^{41,42}$ Total score (range, 0-48) was reversed such that a higher score represented greater spiritual suffering. Items from the Functional Assessment of Chronic Illness Therapy-Palliative Care scale were used to measure patients' physical symptoms (pain, breathlessness, constipation, weight loss, vomiting, swelling in body parts, dryness of mouth and throat, lack of energy, nausea, and other symptoms). The total score ranged from 0 to 40 , a higher score indicated greater physical suffering. ${ }^{35,43}$ Functional suffering was assessed as limitation in activities of daily living using the Older American Resources and Services Multidimensional Functional Assessment Questionnaire. ${ }^{35,44}$ This is a 7-item scale, assessing patient's ability (as "completely unable to do" or "do with some help" [score of 1], or "do without help" [score of 0]) to eat, dress/undress, take care of own appearance, walk, get in/ out of bed, take a bath, and use the bathroom. Item scores were summed (range, 0-7), with a higher score indicating greater functional suffering.

\section{Patient Sociodemographics}

Sociodemographics included age at death (less than median age of 62 years/above the median age), highest education (primary or lower/secondary/above secondary), and religion (Christianity/Islam/other religions, including Buddhism, Taoism, Hinduism, and Sikhism/ free thinker or no religious affiliation).

\section{Healthcare Utilization}

Number of hospital admissions and length of hospital stay were assessed using billing records. Billing records from the last year of life were determined based on date of admission and date of death. Use of palliative/hospice care since diagnosis was assessed from survey self-report.

\section{Place of Death}

Place of death (home, hospital, hospice/care home) was determined from medical records and caregiver self-reports.

\section{Statistical Analysis}

We analyzed data of patients who died between September 2016 and December 2019 and who had answered at least 1 survey during their last year of life. Time axis was represented as time prior to death (in months, $0-12$ months).

Group-based multitrajectory modeling was used to assess the heterogeneity in patterns of change in the 4 considered dimensions of suffering over time. Group-based trajectory modeling (GBTM) is a statistical method that identifies latent groups of patients sharing similar trajectories over time for a particular outcome of interest. ${ }^{45,46}$ Group-based multitrajectory modeling, an extension of GBTM, allowed us to model the trajectories of the 4 dimensions of suffering jointly. ${ }^{47}$

We modeled psychological, spiritual, and physical suffering scores assuming a censored normal distribution and identity link, and functional suffering score using a Poisson distribution and link. Because the number of trajectories and the apt polynomial function (ie, intercept, linear, quadratic, cubic, quartic, quintic) of the trajectory for each suffering dimension were not known a priori, we systematically 
tested a series of model specifications, varying the number of trajectories and the polynomial function of the trajectory for each suffering dimension, to select the model with the best fit. We considered Bayesian information criterion (BIC), value of trajectory membership probability (at least $5 \%$ ), and value of average posterior probability (threshold, 0.7) to choose optimal number of trajectories, aiming for parsimony in the number of trajectories.$^{45}$ For determining the best-fitting polynomial functional of the trajectory for each suffering dimension within a specified number of trajectories, we first specified a quintic (order of 5) polynomial function, and then moved down sequentially by an order of 1 if the specified function was not significant.

We assessed sociodemographic predictors (age, education, and religion) of membership of delineated trajectories. We assessed the association of trajectories (independent variable) with number of hospital admissions and length of hospital stay during the last year of life using negative binomial regressions; with having ever used palliative/hospice care using logistic regression; and with place of death (home/hospice or care home/hospital) using a multinomial logistic regression. Models controlled for patients' age at death, gender, education, and religion.

As a sensitivity analysis, we conducted group-based multitrajectory modeling with the analytical sample restricted to patients with complete information (ie, no missing survey after recruitment and in the 12 months before death) on all 4 suffering outcomes. We determined the proportion of patients classified into similar trajectories in the main and sensitivity analyses.

\section{Results}

Among the 600 patients who participated in COMPASS, $354(59.0 \%)$ died during the study period (supplemental eFigure 1, available with this article at JNCCN.org). Among them, 345 (97\%) patients answered at least 1 survey during their last year of life, thus forming the analysis cohort for this study. The distribution of missing data are presented in supplemental eTable 1.

Details of patient demographics, healthcare utilization, and place of death are provided in Table 1. To determine the appropriate number of trajectories and shape for each trajectory therein, we fitted 40 models (with no covariates). From these, we selected a model with 5 trajectories (BIC, -10,574.38; average posterior probabilities of trajectory membership, 0.88-0.97). We named these distinct trajectories as: (1) persistently low suffering, (2) slowly increasing suffering, (3) predominantly spiritual suffering, (4) rapidly increasing suffering, and (5) persistently high suffering (Figure 1).

Among all the trajectories, patients with the persistently low suffering trajectory (47\%) reported the lowest level of psychological and physical suffering, which

\section{Table 1. Patient Characteristics}

\begin{tabular}{|c|c|}
\hline Characteristic & n (\%) \\
\hline Total, N & 345 \\
\hline \multicolumn{2}{|l|}{ Demographic characteristics } \\
\hline Age at death (range, 27-90), median [SD], y & $62[10.6]$ \\
\hline \multicolumn{2}{|l|}{ Highest educational attainment } \\
\hline Primary or lower & $147(42.6)$ \\
\hline Secondary & $113(32.8)$ \\
\hline Above secondary & $85(24.6)$ \\
\hline \multicolumn{2}{|l|}{ Religion } \\
\hline Christianity & $75(21.7)$ \\
\hline Islam & $60(17.4)$ \\
\hline Others $^{a}$ & $170(49.3)$ \\
\hline No religious affiliation & $40(11.6)$ \\
\hline \multicolumn{2}{|l|}{ Cancer type } \\
\hline Gastrointestinal & $103(29.9)$ \\
\hline Genitourinary/Gynecologic & $62(18.0)$ \\
\hline Respiratory & $98(28.4)$ \\
\hline Breast and others & $82(23.8)$ \\
\hline \multicolumn{2}{|c|}{ Suffering dimensions at the beginning of the last year of life, mean [SD] } \\
\hline Psychological suffering (range, 0-39) & $6.6[6.0]$ \\
\hline Spiritual suffering (range, 0-43) & $11.2[8.3]$ \\
\hline Physical suffering (range, 0-29) & $7.0[6.2]$ \\
\hline Functional suffering (range, 0-5) & $0.4[0.7]$ \\
\hline \multicolumn{2}{|l|}{ Healthcare utilization during last year of life ${ }^{b}$} \\
\hline $\begin{array}{l}\text { Number of hospital admissions } \\
\text { (range, } 0-14 \text {; median, 3), mean [SD] }\end{array}$ & $3.2[2.3]$ \\
\hline $\begin{array}{l}\text { Hospital LoS, d } \\
\text { (range, 0-122d; median, 18), mean [SD] }\end{array}$ & $23.3[21.7]$ \\
\hline Had $>1$ ED visit & $170(51.0)$ \\
\hline \multicolumn{2}{|l|}{ Place of death ${ }^{c}$} \\
\hline Hospital & $167(62.3)$ \\
\hline Home & $67(25.0)$ \\
\hline Hospice/Care home & $34(12.6)$ \\
\hline Ever used palliative/hospice care service & $103(29.9)$ \\
\hline
\end{tabular}

Abbreviations: ED, emergency department; LoS, length of stay.

alncluding Buddhism/Taoism/Hinduism/Sikhism.

bUsing subsample of participants who died before October 2019 ( $n=333)$.

'Using subsample of participants with available information on place of death $(n=268)$.

increased only slightly through the last year of life. Patients' spiritual suffering also remained low throughout, and their functional suffering increased slightly in the last 2 months of life.

Patients with slowly increasing suffering (14\%) had relatively low levels of physical, psychological, spiritual, and functional suffering early in the last year of life, but these slowly increased over the year. Deterioration in functional suffering was more marked in the latter half of the last year of life. They were more likely to have ever used palliative/ 

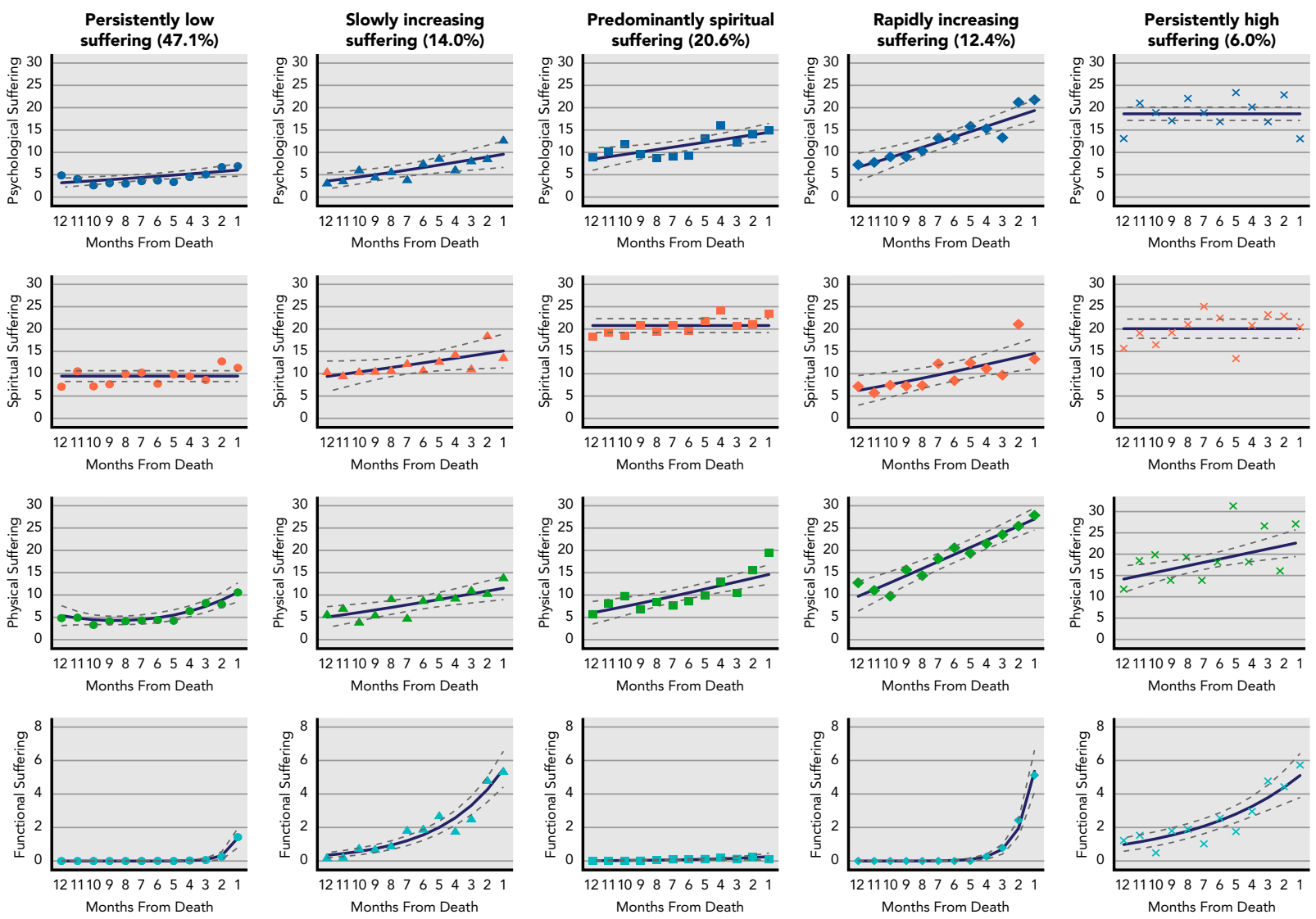

Figure 1. Trajectories of psychological, spiritual, physical, and functional suffering during the last year of life $(N=345)$.

hospice care than patients with persistently low suffering (Table 2).

Patients with predominantly spiritual suffering (21\%) experienced low functional but high spiritual suffering throughout the last year of life. Their physical and psychological suffering increased slowly through the year. Compared with having persistently low suffering, age $\leq 62$ years at death was associated with a higher likelihood of having this trajectory, and being affiliated with any religion versus having no religious affiliation was linked with a lower likelihood (Tables 2 and 3).

Rapidly increasing suffering (12\%) denoted a rapid increase in physical, psychological, and spiritual suffering through the last year of life, along with a rapid increase in functional suffering in the last 3 months. Having secondary (high school) education increased the likelihood of patients having this trajectory compared with persistently low suffering. Patients with this trajectory were likely to have more hospital admissions, a longer hospital stay, and to have ever used palliative/hospice care versus those with persistently low suffering (Tables 2 and 3).

The trajectory with the least proportion of patientspersistently high suffering (6\%) - comprised those with relatively high psychological and spiritual suffering early in the last year of life, which persisted throughout the year. Their physical and functional suffering also increased rapidly through the year. Patients with this trajectory also experienced longer hospital stay, were more likely to have ever used palliative/hospice care, and were more likely to die in hospice versus those with persistently low suffering (Tables 3 and 4).

\section{Sensitivity Analysis $(\mathrm{n}=207)$}

The 5-group model had the BIC closet to zero $(-6,945.29)$ and the average posterior probability of trajectory membership ranged between 0.89 and 1.0 (supplemental eFigure 2). A total of $77 \%$ of patients belonged to similar trajectory groups in the main and complete case analyses.

\section{Discussion}

We describe, for the first time, that suffering during the last year of life of patients with a solid metastatic cancer has variable trajectories. Understanding this variation and its relationship to patient demographics, hospitalizations, and place of death is important for efforts to reduce suffering at the end of life among patients with cancer. 
Table 2. Predictors of Membership of the Trajectories ( $N=345)$

\begin{tabular}{|c|c|c|c|c|c|c|c|c|}
\hline & \multicolumn{2}{|c|}{ Slowly Increasing Suffering ${ }^{a}$} & \multicolumn{2}{|c|}{ Predominantly Spiritual Suffering $^{a}$} & \multicolumn{2}{|c|}{ Rapidly Increasing Suffering ${ }^{a}$} & \multicolumn{2}{|c|}{ Persistently High Suffering ${ }^{a}$} \\
\hline & $\begin{array}{l}\text { Coefficient } \\
\text { (SE) }\end{array}$ & $95 \% \mathrm{Cl}$ & $\begin{array}{l}\text { Coefficient } \\
\text { (SE) }\end{array}$ & $95 \% \mathrm{Cl}$ & $\begin{array}{l}\text { Coefficient } \\
\text { (SE) }\end{array}$ & $95 \% \mathrm{Cl}$ & $\begin{array}{l}\text { Coefficient } \\
\text { (SE) }\end{array}$ & $95 \% \mathrm{Cl}$ \\
\hline $\begin{array}{l}\text { Aged } \leq 62 \text { y at } \\
\text { death (median) }\end{array}$ & $0.60(0.42)$ & -0.22 to 1.42 & $1.57^{\mathrm{b}}(0.51)$ & 0.58 to 2.56 & $0.46(0.53)$ & -0.58 to 1.51 & $1.07^{c}(0.65)$ & -0.20 to 2.34 \\
\hline \multicolumn{9}{|c|}{ Highest educational attainment (ref: primary or lower) } \\
\hline Secondary & $0.51(0.46)$ & -0.38 to 1.41 & $-0.04(0.55)$ & -1.11 to 1.03 & $1.25^{\mathrm{b}}(0.61)$ & 0.05 to 2.45 & $1.00(0.78)$ & -0.52 to 2.53 \\
\hline $\begin{array}{l}\text { Above } \\
\text { secondary }\end{array}$ & $0.12(0.52)$ & -0.89 to 1.14 & $-1.14^{\mathrm{c}}(0.66)$ & -2.44 to 0.16 & $1.20^{\mathrm{c}}(0.67)$ & -0.11 to 2.50 & $0.61(0.88)$ & -1.12 to 2.34 \\
\hline \multicolumn{9}{|c|}{ Religion (ref: no religious affiliation) } \\
\hline Christianity & $-0.29(0.80)$ & -1.85 to 1.27 & $-1.89^{b}(0.82)$ & -3.49 to -0.29 & $1.84(1.69)$ & -1.47 to 5.16 & $-1.43(1.05)$ & -3.49 to 0.63 \\
\hline Islam & $0.18(0.78)$ & -1.34 to 1.71 & $-1.76^{\mathrm{b}}(0.77)$ & -3.26 to -0.25 & $1.59(1.70)$ & -1.73 to 4.92 & $-0.95(0.93)$ & -2.78 to 0.87 \\
\hline $\begin{array}{l}\text { Other } \\
\text { religions }^{d}\end{array}$ & $-0.40(0.81)$ & -1.98 to 1.18 & $-3.84^{b}(1.01)$ & -5.81 to -1.86 & $1.12(1.71)$ & -2.24 to 4.48 & $-1.97^{\mathrm{c}}(1.09)$ & -4.11 to 0.16 \\
\hline
\end{tabular}

${ }^{a}$ Reference trajectory: persistently low suffering.

${ }^{\text {b }}$ Statistically significant at the $5 \%$ level.
'Statistically significant at the $10 \%$ level.

IIncluding Buddhism/Taoism/Hinduism/Sikhism.
Notably, half of our patient sample, with persistently low suffering, reported little or no suffering early in their last year of life. This is consistent with the description of the average trajectory for patients with cancer in the literature. ${ }^{13,14}$ Given that our study was conducted in Singapore, which is a high-income country with a high performing health system and ranking 12th (in a list of 80 countries) on the 2015 Quality of Death Index, ${ }^{48}$ it is likely that the proportion of patients with cancer experiencing persistently low suffering in the last year of life would be lower in many countries with fewer healthcare resources. In Singapore, palliative care services are provided in acute care hospitals (outpatient and inpatient care), subacute care settings (community hospitals), and hospices (home care, day care, and inpatient care). Patients are referred to these services by their treating physician based on eligibility. Care is provided by multidisciplinary teams, mostly consisting of medical social workers, physicians, nurses, and trained volunteers. ${ }^{49-53}$

For the remaining half of the patients who were likely to experience suffering in $\geq 1$ dimension early in the last year of life, systematic and frequent monitoring of suffering should be conducted. Given that increase in suffering in 1 dimension does not mirror increase in another, assessment should encompass all dimensions of suffering. For example, patients with predominantly spiritual suffering

\begin{tabular}{|c|c|c|c|c|c|c|c|c|}
\hline \multirow[b]{2}{*}{ Trajectory } & \multicolumn{2}{|c|}{$\begin{array}{c}\text { Number of Hospital } \\
\text { Admissions }^{\mathrm{a}} \\
\text { (Range, 0-14; Median, 3) }^{\text {(Ra) }}\end{array}$} & \multicolumn{2}{|c|}{$\begin{array}{c}\text { Length of Hospital } \\
\text { Stay }^{\mathrm{a}} \\
\text { (Range, 0-122; Median, 18) }\end{array}$} & \multicolumn{2}{|c|}{$\begin{array}{l}\text { Had >1 Emergency } \\
\text { Department Visit }\end{array}$} & \multicolumn{2}{|c|}{$\begin{array}{l}\text { Ever Used Palliative/ } \\
\text { Hospice Care Service }^{\text {b }}\end{array}$} \\
\hline & $\begin{array}{l}\text { Coefficient } \\
\quad \text { (SE) }\end{array}$ & $95 \% \mathrm{Cl}$ & $\begin{array}{l}\text { Coefficient } \\
\quad \text { (SE) }\end{array}$ & $95 \% \mathrm{Cl}$ & $\begin{array}{l}\text { Coefficient } \\
\text { (SE) }\end{array}$ & $95 \% \mathrm{Cl}$ & $\begin{array}{l}\text { Coefficient } \\
\quad \text { (SE) }\end{array}$ & $95 \% \mathrm{Cl}$ \\
\hline $\begin{array}{l}\text { Slowly increasing } \\
\text { suffering }\end{array}$ & $0.01(0.12)$ & -0.22 to 0.23 & $0.2(0.16)$ & -0.12 to 0.52 & $0.10(0.34)$ & -0.56 to 0.77 & $1.78^{d}(0.37)$ & 1.05 to 2.51 \\
\hline $\begin{array}{l}\text { Predominantly } \\
\text { spiritual } \\
\text { suffering }^{c}\end{array}$ & $-0.09(0.11)$ & -0.30 to 0.13 & $-0.09(0.15)$ & -0.38 to 0.20 & $-0.62^{\mathrm{e}}(0.32)$ & -1.24 to 0.01 & $0.39(0.38)$ & -0.36 to 1.14 \\
\hline $\begin{array}{l}\text { Rapidly } \\
\text { increasing } \\
\text { suffering }^{c}\end{array}$ & $0.24^{d}(0.12)$ & 0 to 0.47 & $0.40^{d}(0.18)$ & 0.04 to 0.75 & $0.53(0.38)$ & -0.21 to 1.27 & $2.02^{d}(0.40)$ & 1.24 to 2.79 \\
\hline $\begin{array}{l}\text { Persistently high } \\
\text { suffering }^{c}\end{array}$ & $-0.04(0.17)$ & -0.38 to 0.30 & $0.70^{d}(0.24)$ & 0.23 to 1.17 & $0.48(0.51)$ & -0.52 to 1.48 & $2.65^{d}(0.55)$ & 1.58 to 3.73 \\
\hline
\end{tabular}

All estimates were adjusted for age at death, sex, highest education, and religion. Subsample of participants who died before October 2019 ( $n=333$ ).

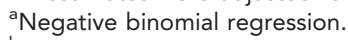

bLogistic regression.

'Ref: persistently low suffering.

${ }^{\mathrm{d}}$ Statistically significant at the $5 \%$ level.

eStatistically significant at the $10 \%$ level. 
Table 4. Association of the Delineated Trajectories With Place of Death $(\mathbf{N}=\mathbf{2 6 8})$

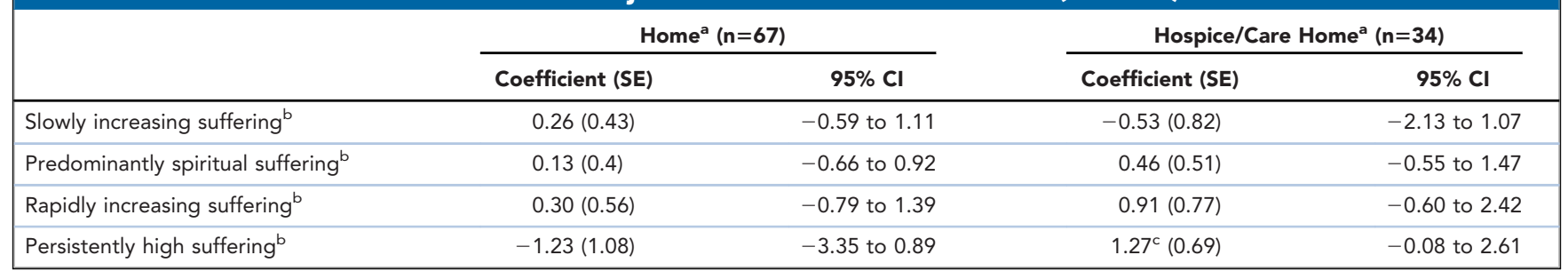

Multinomial logistic regression, adjusting for age at death, gender, highest education, and religion. Subsample of participants with available information on place of death $(n=268)$.

a Ref: hospital ( $n=167)$.

${ }^{b}$ Ref: persistently low suffering

'Statistically significant at the $10 \%$ level.

who experienced high spiritual suffering but no functional suffering may benefit from support to alleviate spiritual suffering. This group was more likely to comprise patients with no religious affiliation and younger adults (consistent with hypothesis), which explains the high spiritual suffering and low level of functional suffering. ${ }^{24-26}$

Patients with higher education (indicative of a high socioeconomic status [SES]) were more likely to have the trajectory that denoted high suffering across all dimensions-rapidly increasing suffering. Approximately $31 \%$ of health expenditure in Singapore is out-of-pocket. ${ }^{54}$ As a result, patients with high SES may be able to afford and choose to manage their cancer more aggressively than those with low SES, and may inadvertently experience greater suffering. Some previous studies also observe that patients with high SES report greater suffering. ${ }^{55,56}$

Consistent with the hypothesis, we found that patients having trajectories that denoted the highest extent of suffering across all dimensions (rapidly increasing suffering and persistently high suffering constituting $18 \%$ of the sample) had the highest number of hospital admissions and longest hospital stay. The direction of relationship between hospitalizations and suffering is not immediately clear and requires further investigation. Past studies have reported that hospitalizations influence activities of daily living (functional suffering) and physical and psychological suffering during the last year of life, rather than the other way around. ${ }^{28,57,58}$ If confirmed, efforts to reduce hospitalizations during the last year of life can have beneficial effects in terms of reducing patients' suffering.

Last, patients having trajectories with greater psychological, spiritual, and physical suffering than persistently low suffering were more likely to have been referred to a palliative/hospice care service because of their greater levels of suffering.

Our results have clinical implications. We recommend that that healthcare providers systematically and frequently monitor patients with advanced cancer at risk for dying within 1 year to assess their suffering. Monitoring of suffering should be comprehensive across its psycho- logical, spiritual, physical, and functional dimensions. Patients vulnerable to experiencing greater levels of suffering (younger patients, those with above secondary education, those with no religious affiliation, and those with frequent hospital admissions) warrant closer attention and more frequent monitoring. Hospitalized patients with cancer likely to die within a year and those experiencing suffering in $\geq 1$ dimensions should receive a timely referral to palliative care services. Multidisciplinary palliative care teams offer symptom management, psychological and spiritual support, advance care planning, and nursing care. ${ }^{59}$ Evidence suggests that referrals to such care can reduce patients' physical, psychological, and spiritual suffering and prevent acute hospital admissions. ${ }^{60-64}$

The main strength of our study is that our results are based on prospective longitudinal data with multiple assessments conducted exclusively with patients. In contrast, some previous studies have either used crosssectional data ${ }^{14}$ or relied on both patient and caregiver reports, even though literature suggests that caregivers' reports may not reflect patients' perception of their condition accurately. ${ }^{65,66}$

Our study has limitations. First, assessments of suffering were conducted every 3 months (maximum, 5 months). More frequent assessments would have enabled us to describe fluctuations in trajectory with greater precision by increasing the sample size at single-month time points during the last year of life. Second, we were unable to extract data regarding hospitalizations and place of death for participants who died between October and December 2019, reducing the sample size for assessing the association of these variables with the delineated trajectories. Nonetheless, we did find meaningful associations. Third, $14 \%$ of the patient data during their last year of life was missing, including $49 \%$ of the data in the last month. It is possible that the missing data were not at random and that missing observations represented a higher degree of suffering. However, our analytic method uses full-information maximum likelihood to handle missing data. This method includes data from all patients regardless of whether they 
had missing information, and the mean and variance of the missing observations for a variable, given the recorded observations of the variables. ${ }^{67-69}$ It is less biased and more efficient than other ways of handling missing data ${ }^{67,70,71}$ Results from our sensitivity analysis (complete case analysis) also agree with the main analysis. Fourth, differential reporting of suffering between patients from higher and lower levels of education may have been possible. ${ }^{72}$ Fifth, the scale for assessment of functional suffering in our sample has primarily been validated for use among older patients with cancer. Last, our outcome regarding use of palliative/hospice care was self-reported, which may be subject to recall issues. The exact time of referral to these services was also not known.

Future research should further clarify the relationship between suffering and acute hospital admissions, identify whether patients with certain cancer types or clinical characteristics experience trajectories with greater suffering, and confirm the generalizability of our results in different settings and cultural contexts. Additionally, future studies should assess the influence of psychosocial history, past trauma, and current social environment on trajectories of suffering during the last year of life.

\section{Conclusions}

Our results show 5 trajectories of suffering based on varying levels of psychological, spiritual, physical, and functional suffering during the last year of life of patients with advanced cancer. We show that these trajectories are associated with patients' hospitalizations, palliative/hospice care use, and their education (indicative of SES), lending further validity to their presence. Understanding this variation can facilitate clinical decisions to timely refer patients to palliative care to reduce their suffering and healthcare costs at the end of life.

Submitted October 15, 2020; final revision received December 21, 2020; accepted for publication January 23, 2021.

Published online September 7, 2021.

Author contributions: Study concept and design: C. Malhotra. Data acquisition: Finkelstein. Data analysis and interpretation: C. Malhotra, R. Malhotra, Bundoc. Manuscript preparation: C. Malhotra, R. Malhotra, Bundoc. Critical input: Teo, Ozdemir, Chan, Finkelstein. Final approval of manuscript: All authors.

Disclosures: The authors have disclosed that they have not received any financial consideration from any person or organization to support the preparation, analysis, results, or discussion of this article.

Funding: This work was supported by funding from Singapore Millennium Foundation (2015-SMF-0003) and Lien Centre for Palliative Care (LCPC-IN14-0003).

Correspondence: Chetna Malhotra, MD, Lien Centre for Palliative Care, Duke-NUS Medical School, 8 College Road, Singapore 169857.

Email: Chetna.malhotra@duke-nus.edu.sg

\section{References}

1. National Cancer Institute. Cancer Statistics. Accessed December 22, 2020 Available at: https://www.cancer.gov/about-cancer/understanding/ statistics

2. Knaul FM, Farmer PE, Krakauer EL, et al. Alleviating the access abyss in palliative care and pain relief-an imperative of universal health coverage: the Lancet Commission report. Lancet 2018;391:1391-1454.

3. World Health Organization. Strengthening of palliative care as a component of integrated treatment throughout the life course. J Pain Palliat Care Pharmacother 2014;28:130-134.

4. Sleeman KE, de Brito $M$, Etkind $S$, et al. The escalating global burden of serious health-related suffering: projections to 2060 by world regions, age groups, and health conditions. Lancet Glob Health 2019;7:e883-892.

5. Knaul F, Bhadelia A, Rodriguez N, et al. The Lancet Commission on Palliative Care and Pain Relief-findings, recommendations, and future directions. Lancet Glob Health 2018;6:S5-6.

6. World Health Assembly. Strengthening of palliative care as a component of comprehensive care throughout the life course. Document WHA67.19; May 24, 2014. Accessed December 20, 2020. Available at: https://apps. who.int/iris/handle/10665/162863

7. Krikorian A, Limonero JT, Maté J. Suffering and distress at the end-of-life. Psychooncology 2012;21:799-808

8. Cassell EJ, Rich BA. Intractable end-of-life suffering and the ethics of palliative sedation. Pain Med 2010;11:435-438.

9. Cassel EJ. The nature of suffering and the goals of medicine. N Engl J Med 1982;306:639-645.

10. Coulehan J. Compassionate solidarity: suffering, poetry, and medicine. Perspect Biol Med 2009;52:585-603.

11. Bueno-Gómez N. Conceptualizing suffering and pain. Philos Ethics Humanit Med 2017;12:7

12. Chen JH, Chan DC, Kiely DK, et al. Terminal trajectories of functional decline in the long-term care setting. J Gerontol A Biol Sci Med Sci 2007; 62:531-536.

13. Gill TM, Gahbauer EA, Han L, et al. Trajectories of disability in the last year of life. N Engl J Med 2010;362:1173-1180.
14. Lunney JR, Lynn J, Foley DJ, et al. Patterns of functional decline at the end of life. JAMA 2003;289:2387-2392.

15. Wolf DA, Freedman VA, Ondrich JI, et al. Disability trajectories at the end of life: a "countdown" model. J Gerontol B Psychol Sci Soc Sci 2015;70: 745-752

16. Kwak M, Zebrack BJ, Meeske KA, et al. Trajectories of psychological distress in adolescent and young adult patients with cancer: a 1-year longitudinal study. J Clin Oncol 2013;31:2160-2166.

17. Lo C, Zimmermann C, Rydall A, et al. Longitudinal study of depressive symptoms in patients with metastatic gastrointestinal and lung cancer. J Clin Oncol 2010;28:3084-3089.

18. Adler NE, Newman K. Socioeconomic disparities in health: pathways and policies. Health Aff (Millwood) 2002;21:60-76.

19. Ross CE, Wu C. The links between education and health. Am Soc Rev 1995 60:719-745

20. Winkleby MA, Jatulis DE, Frank E, et al. Socioeconomic status and health how education, income, and occupation contribute to risk factors for cardiovascular disease. Am J Public Health 1992;82:816-820.

21. Tomic K, Ventimiglia E, Robinson D, et al. Socioeconomic status and diagnosis, treatment, and mortality in men with prostate cancer. Nationwide population-based study. Int J Cancer 2018;142:2478-2484.

22. Lago-Peñas S, Rivera B, Cantarero D, et al. The impact of socioeconomic position on non-communicable diseases: what do we know about? Perspect Public Health 2021;141:158-176.

23. Larsen IK, Myklebust TÅ, Babigumira R, et al. Education, income and risk of cancer: results from a Norwegian registry-based study. Acta Oncol 2020; 59:1300-1307.

24. Garman KS, Cohen HJ. Functional status and the elderly cancer patient. Crit Rev Oncol Hematol 2002;43:191-208.

25. Thomé B, Dykes AK, Hallberg IR. Quality of life in old people with and without cancer. Qual Life Res 2004;13:1067-1080.

26. White HK, Cohen HJ. The older cancer patient. Nurs Clin North Am 2008; 43:307-322 
27. Balboni TA, Vanderwerker LC, Block SD, et al. Religiousness and spiritual support among advanced cancer patients and associations with end-of-life treatment preferences and quality of life. J Clin Oncol 2007;25:555-560.

28. Gill TM, Gahbauer EA, Han L, et al. The role of intervening hospital admissions on trajectories of disability in the last year of life: prospective cohort study of older people. BMJ 2015;350:h2361.

29. O'Hare AM, Hailpern SM, Wachterman M, et al. Hospice use and end-oflife spending trajectories in Medicare beneficiaries on hemodialysis. Health Aff (Millwood) 2018;37:980-987.

30. Nagurney JM, Fleischman W, Han L, et al. Emergency department visits without hospitalization are associated with functional decline in older persons. Ann Emerg Med 2017;69:426-433.

31. Nipp RD, El-Jawahri A, Moran SM, et al. The relationship between physical and psychological symptoms and health care utilization in hospitalized patients with advanced cancer. Cancer 2017; 123:4720-4727

32. Gomes B, Calanzani N, Koffman J, et al. Is dying in hospital better than home in incurable cancer and what factors influence this? A populationbased study. BMC Med 2015;13:235.

33. Pinzón LCE, Claus M, Zepf Kl, et al. Symptom prevalence in the last days of life in Germany: the role of place of death. Am J Hosp Palliat Care 2012;29: 431-437.

34. Wadhwa D, Popovic G, Pope A, et al. Factors associated with early referral to palliative care in outpatients with advanced cancer. J Palliat Med 2018; 21:1322-1328.

35. Teo I, Singh R, Malhotra C, et al. Cost of Medical Care of Patients with Advanced Serious Illness in Singapore (COMPASS): prospective cohort study protocol. BMC Cancer 2018;18:459.

36. Conill C, Verger E, Salamero M. Performance status assessment in cancer patients. Cancer 1990;65:1864-1866.

37. Azam F, Latif MF, Farooq A, et al. Performance status assessment by using ECOG (Eastern Cooperative Oncology Group) score for cancer patients by oncology healthcare professionals. Case Rep Oncol 2019;12:728-736.

38. Beck KR, Tan SM, Lum SS, et al. Validation of the emotion thermometers and hospital anxiety and depression scales in Singapore: screening cancer patients for distress, anxiety and depression. Asia Pac J Clin Oncol 2016;12: e241-249

39. Zigmond AS, Snaith RP. The hospital anxiety and depression scale. Acta Psychiatr Scand 1983;67:361-370.

40. Djukanovic I, Carlsson J, Årestedt K. Is the Hospital Anxiety and Depression Scale (HADS) a valid measure in a general population 65-80 years old? A psychometric evaluation study. Health Qual Life Outcomes 2017;15:193.

41. Malhotra C, Harding R, Teo I, et al. Financial difficulties are associated with greater total pain and suffering among patients with advanced cancer: results from the COMPASS study. Support Care Cancer 2020;28:37813789.

42. Peterman AH, Fitchett $G$, Brady MJ, et al. Measuring spiritual well-being in people with cancer: the functional assessment of chronic illness therapySpiritual Well-being Scale (FACIT-Sp). Ann Behav Med 2002;24:49-58.

43. Lyons KD, Bakitas M, Hegel MT, et al. Reliability and validity of the functional assessment of chronic illness therapy-palliative care (FACIT-pal) scale. J Pain Symptom Manage 2009;37:23-32.

44. Fillenbaum GG. Multidimensional Functional Assessment of Older Adults: The Duke Older Americans Resources and Services Procedures. New York, NY: Psychology Press; 2013.

45. Nagin DS. Group-Based Modeling of Development. Cambridge, MA: Harvard University Press; 2005.

46. Nagin DS, Tremblay RE. Analyzing developmental trajectories of distinct but related behaviors: a group-based method. Psychol Methods 2001;6: 18-34.

47. Nagin DS, Jones BL, Passos VL, et al. Group-based multi-trajectory modeling. Stat Methods Med Res 2018;27:2015-2023

48. The Economist Intelligence Unit. The 2015 Quality of Death Index: Ranking Palliative Care Across the World. New York; 2015. Available at: http://www. lienfoundation.org/sites/default/files/2015\%20Quality\%20of\%20Death\% 20Report.pdf

49. Singapore Hospice Council. Palliative Care Services. Accessed December 9, 2020. Available at: https://singaporehospice.org.sg/services/
50. Lien Centre for Palliative Care - Duke-NUS Medical School. About Palliative Care. Accessed December 9, 2020. Available at: https://www.duke-nus. edu.sg/lcpc/about-palliative-care

51. Lin Goh SS. Singapore takes six steps forward in 'The Quality of Death Index' rankings. Asia Pac J Oncol Nurs 2018;5:21-25.

52. Poon E, O'Connor M. Development of palliative care in Singapore: an overview. Singapore Nursing Journal 2009;36:48-56.

53. Poulose JV, Do YK, Neo PSH. Association between referral-to-death interval and location of death of patients referred to a hospital-based specialist palliative care service. J Pain Symptom Manage 2013;46:173181.

54. The World Bank. World Health Organization Global Health Expenditure database. 2020. Accessed December 17, 2020. Available at: https://apps. who.int/nha/database/country_profile/Index/en

55. Wong SL, Gu N, Banerjee $\mathrm{M}$, et al. The impact of socioeconomic status on cancer care and survival [abstract]. J Clin Oncol 2011;29(Suppl):Abstract 6004

56. Wilson KG, Chochinov HM, McPherson CJ, et al. Suffering with advanced cancer. J Clin Oncol 2007;25:1691-1697.

57. Covinsky KE, Pierluissi E, Johnston CB. Hospitalization-associated disability: "she was probably able to ambulate, but I'm not sure". JAMA 2011; 306:1782-1793.

58. Gill TM, Allore HG, Gahbauer EA, et al. Change in disability after hospitalization or restricted activity in older persons. JAMA 2010;304:19191928.

59. Hui D, Hannon BL, Zimmermann C, et al. Improving patient and caregive outcomes in oncology: team-based, timely, and targeted palliative care. CA Cancer J Clin 2018;68:356-376.

60. Temel JS, Greer JA, Muzikansky A, et al. Early palliative care for patients with metastatic non-small-cell lung cancer. N Engl J Med 2010;363:733742.

61. Zimmermann C, Swami N, Krzyzanowska M, et al. Early palliative care for patients with advanced cancer: a cluster-randomised controlled trial. Lancet 2014;383:1721-1730.

62. Haun MW, Estel S, Rücker G, et al. Early palliative care for adults with advanced cancer. Cochrane Database Syst Rev 2017;6:CD011129.

63. Bakitas M, Lyons KD, Hegel MT, et al. Effects of a palliative care intervention on clinical outcomes in patients with advanced cancer: the Project ENABLE II randomized controlled trial. JAMA 2009;302:741-749.

64. Kavalieratos D, Corbelli J, Zhang D, et al. Association between palliative care and patient and caregiver outcomes: a systematic review and metaanalysis. JAMA 2016;316:2104-2114.

65. Shin DW, Cho J, Kim SY, et al. Patients' and family caregivers' understanding of the cancer stage, treatment goal, and chance of cure: a study with patient-caregiver-physician triad. Psychooncology 2018;27:106-113.

66. Lee YJ, Kim JE, Choi YS, et al. Quality of life discordance between termina cancer patients and family caregivers: a multicenter study. Support Care Cancer 2016;24:2853-2860

67. Wothke W. Longitudinal and multigroup modeling with missing data. In: Little TD, Schnabel KU, Baumert J, eds. Modeling Longitudinal and Multilevel Data: Practical Issues, Applied Approaches, and Specific Examples. Mahwah, NJ: Lawrence Erlbaum Associates Publishers; 2000:219-240.

68. Nguena Nguefack HL, Pagé MG, Katz J, et al. Trajectory modelling techniques useful to epidemiological research: a comparative narrative review of approaches. Clin Epidemiol 2020;12:1205-1222.

69. Dodge HH, Shen C, Ganguli M. Application of the pattern-mixture latent trajectory model in an epidemiological study with non-ignorable missingness. J Data Sci 2008;6:247-259.

70. Schafer JL, Graham JW. Missing data: our view of the state of the art. Psychol Methods 2002;7:147-177.

71. Schlomer GL, Bauman S, Card NA. Best practices for missing data management in counseling psychology. J Couns Psychol 2010;57:1-10.

72. Hanandita W, Tampubolon G. Does reporting behaviour bias the measurement of social inequalities in self-rated health in Indonesia? An anchoring vignette analysis. Qual Life Res 2016;25:1137-1149. 
Supplemental online content for:

\section{Trajectories of Suffering in the Last Year of Life Among Patients With a Solid Metastatic Cancer}

Chetna Malhotra, MD; Rahul Malhotra, MD; Filipinas Bundoc, MA; Irene Teo, PhD; Semra Ozdemir, PhD; Noreen Chan, MD; and Eric Finkelstein, PhD, MHA

J Natl Compr Canc Netw 2021;19(11):1264-1271

eFigure 1: COMPASS Participant Flow Diagram

eFigure 2: Trajectories During the Last Year of Life Among Those With Complete Information Prior to Death eTable 1: Missing Information Prior to Date of Death 


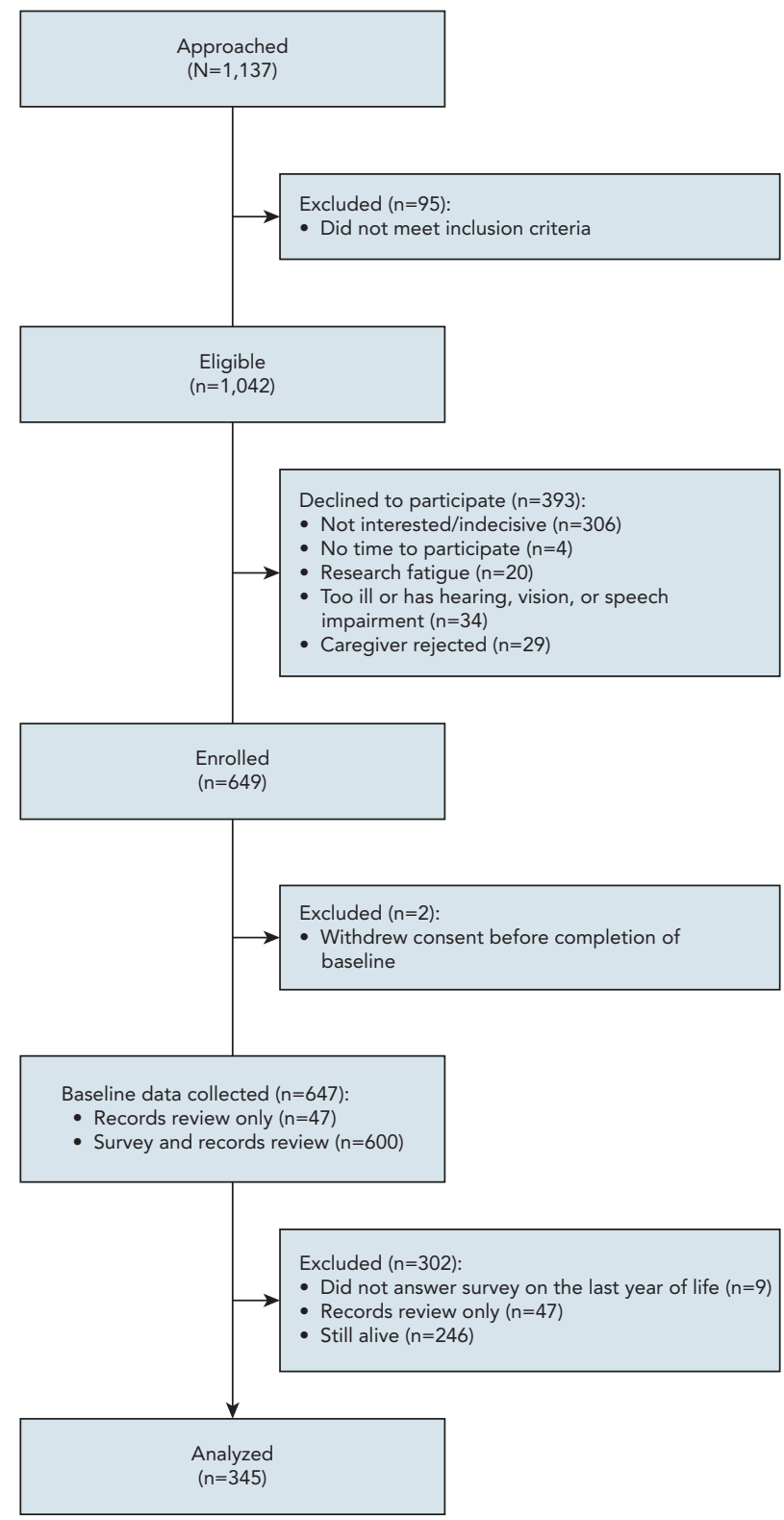

eFigure 1. Cost of Medical Care of Patients with Advanced Serious Illness in Singapore (COMPASS) participant flow diagram. 


\section{2 - Malhotra et al}
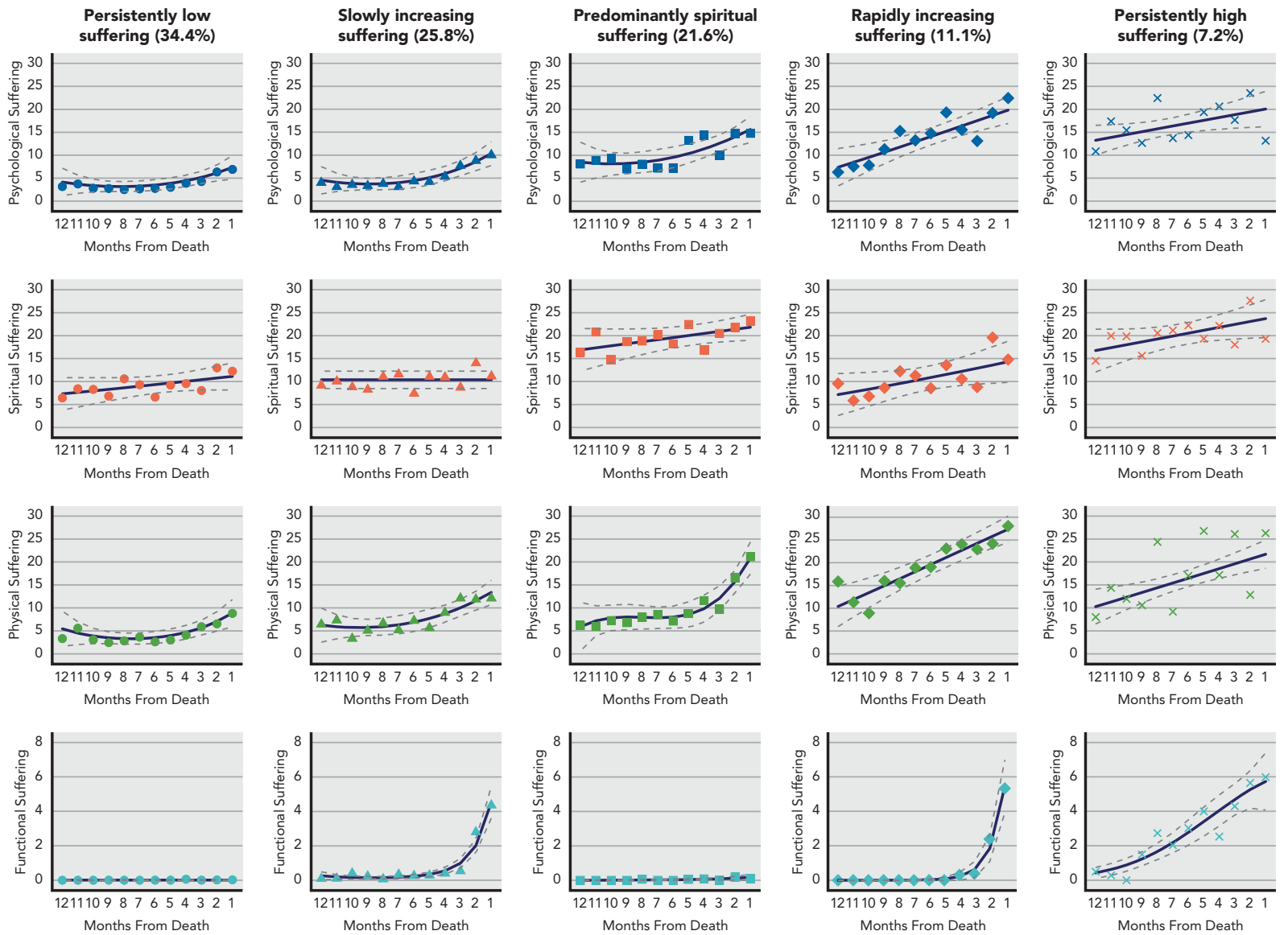

eFigure 2. Trajectories of psychological, spiritual, physical, and functional suffering during the last year of life among those with complete information prior to death $(n=207)$. 
Malhotra et al - 3

\section{eTable 1. Missing Information Prior to Date of}

\section{Death ${ }^{\mathrm{a}}$}

Months From Date of Death n (\%)

\begin{tabular}{ll}
\hline & $72(49.0)$
\end{tabular}

$2 \quad 32(29.6)$

$3 \quad 18(16.5)$

$4 \quad 11(8.7)$

5

$6 \quad 13(12.4)$

$7 \quad 2(2.0)$

$8 \quad 4(4.9)$

$9 \quad 5(5.6)$

$10 \quad 3(3.8)$

$1122(2.7)$

$12 \quad 1(1.47)$

Total 167 (14.1)

${ }^{a} n=345$; number of observations $=1,178$. 